\title{
An overview of the global epidemiology of HIV/AIDS
}

\author{
HELEN A. WEISS* \& SARAH HAWKES** \\ *MRC Tropical Epidemiology Group, London School of Hygiene \& \\ Tropical Medicine, UK \\ **Population Council, South and East Asia Regional Office, New \\ Delhi, India
}

\begin{abstract}
Summary Over 5 million people continue to be newly infected with HIV every year, despite advances in understanding the factors that drive the epidemics. It is apparent that control of the HIV epidemics has often proved difficult due to the complex web of behavioural, biological, social and structural vulnerabilities to infection. In this paper we discuss the epidemiology and control of HIV in sub-Saharan Africa, and draw parallels with the emerging epidemic in South and South-East Asia. Prevalence of infection in sub-Saharan Africa has continued to increase overall, but a few countries have successfully reduced national infection rates by employing an integrated, multisectoral control strategy. Prevention of similar devastating epidemics in other regions will rely upon an openness in recognizing risk and upon a concerted multisectoral approach to reduction of riskof risk at the individual level andlevel and vulnerability at the societal and structural levels.
\end{abstract}

\section{Introduction}

In the past 2 decades, the human immunodeficiency virus (HIV) has rampaged across the globe leaving virtually no country untouched. Despite advances in our understanding of the social, behavioural and biological factors that directly increase the risk of HIV transmission, approximately 14,500 individuals are infected daily. ${ }^{1}$ This high rate of infection has remained constant in recent years, reflecting the difficulties in translating knowledge into better public health.

Over the last 20 years, sub-Saharan Africa has been, and continues to be, the worst affected region, home to 34 million adults and children living with HIV/AIDS, with devastating effects on all aspects of society from family life to international security. To date, no other regions of the world have witnessed a similar degree of devastation, but this may be a temporary phenomenon as the epidemic has arrived relatively recently in

Correspondence to: H. A. Weiss (e-mail: helen.weiss@lshtm.ac.uk, Tel: +44-207-6127872, Fax: +44-2076368739) 
some parts of the world. In this paper we explore the epidemiology of HIV in subSaharan Africa, and draw parallels with the emerging epidemic in South and South-East Asia, which is already home to an estimated 5.8 million adults and children living with HIV/AIDS. ${ }^{1}$

\section{Factors influencing the spread of HIV}

In many parts of the world, the predominant mode of transmission has always been heterosexual contact. However, the rates of HIV seen in different geographical settings vary widely as the result of a complex interplay of behavioural, biological, social and structural risks (direct determinants) and vulnerabilities (i.e. factors which may not be directly linked to the transmission of the virus, but may increase the chances of the virus spreading in a particular population); see Table 1.

At an individual level, vulnerability to HIV infection depends on factors that influence the risk of exposure to the virus, such as rate of partner change or frequency of sexual intercourse with an infected partner, and factors which affect the risk of transmission of the virus, such as condom use or presence of another sexually transmitted infection (STI). Many social and demographic factors also influence the epidemiology of HIV (Table 1). High rates of population mobility or urbanization tend to create groups who have an increased vulnerability to infection. Settings where women have not achieved social and economic equality with men also tend to enhance vulnerability, leading, for example, to women's weaker positions in negotiating safer sex (use of condoms), and women resorting to prostitution in the absence of employment opportunities in more formal sectors.

The interplay of these factors can have a dramatic effect on infection rates. Figure 1 shows HIV prevalence among teenage girls in Kisumu, western Kenya. Almost $30 \%$ of girls aged 17 were HIV positive compared with only $4 \%$ of boys of a similar age. This striking difference suggests that young girls are particularly susceptible to infection, through having unprotected sex with older, infected, men and perhaps due to starting sex at a very young age. ${ }^{2}$

Table 1. Factors influencing risk and vulnerability to HIV

\begin{tabular}{lll}
\hline Individual factors & Social and demographic factors & Structural factors \\
\hline $\begin{array}{l}\text { Protective behaviours (e.g. use } \\
\text { of condoms) }\end{array}$ & Age structure of population & Position of women \\
Type of partnerships & Sexual mixing patterns & Wealth of population \\
Injecting drug use & Population mobility & Income distribution \\
Lack of knowledge & Rates of urbanization & Policy environment \\
Denial of risk & Gender-based education rates & \\
Age & Rates of male circumcision & \\
Gender & Access to effective STI treatment & \\
Presence of other sexually & Availability and use of commercial & \\
transmitted infections (STIs) & sex & \\
Male circumcision status & Services for drug users & \\
& Safety of blood transfusion & \\
\hline
\end{tabular}




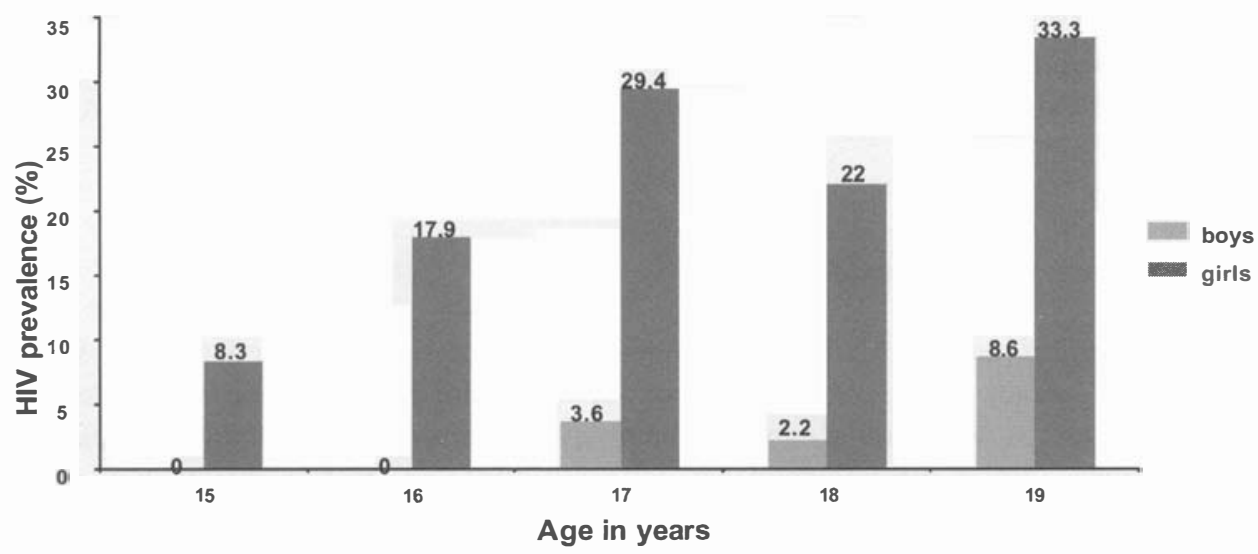

Figure 1. HIV prevalence rate among teenagers in Kisumu, Kenya, by age (source: National AIDS Programme, Kenya, and Population Council, 1999).

\section{Epidemiology of HIV in sub-Saharan Africa}

Sub-Saharan Africa provides ample evidence of differences in prevalence, with most countries in West Africa consistently reporting lower rates than those in Eastern or Southern Africa. To explore the relative importance of the factors listed in Table 1, one recent study compared reported sexual behaviour with data on biological 'co-factors' in four cities. Two were cities with relatively low, and fairly stable prevalence of HIV (Yaounde, Cameroon and Cotonou, Benin), and two were cities in eastern/southern Africa with very high HIV rates Kisumu, Kenya and Ndola, Zambia. ${ }^{3}$ Few differences in sexual behaviour were found, although men and women in the high prevalence cities tended to be younger at first sex and at marriage, features which are likely to have helped drive the epidemics. Biological factors, however, were found to explain more of the variation in HIV rates than differences in sexual behaviour. Other sexually transmitted infections, especially the ones that cause genital ulcers, such as HSV-2, are known to enhance the spread of HIV. ${ }^{4} \mathrm{HSV}-2$ infection is highly prevalent in many African countries. Individuals with both infections are at high risk of transmitting both viruses due to the more frequent recurrences of genital herpes, giving rise to a 'reinforcing epidemic'. This might explain in part why the HIV epidemic has spread so rapidly in countries with high levels of HSV-2 and other sexually transmitted infections.

Another factor that may explain the lower prevalence in most West African countries is the protective effect of male circumcision against acquiring HIV. This hypothesis was first postulated in $1987,{ }^{5}$ and the epidemiological evidence for a strong protective effect (a reduction in risk of around $60 \%$ ) is now compelling. ${ }^{6}$ Such a protective effect is biologically plausible, ${ }^{7}$ but its translation into public health practice is fraught with difficulties, as male circumcision is of ten an important cultural or religious practice. Further, there is the concern that men may alter their sexual behaviour if they believe they are protected from infection by circumcision.

\section{Strategies to reduce heterosexual transmission of HIV}

In the absence of a vaccine against HIV, current prevention strategies focus on changing 
sexual behaviour and on creating a social environment that reduces a population's vulnerability to the epidemic. Such strategies include promoting the use of condoms, directing STI treatment programmes at specific populations that are at high risk, community-wide programmes to reduce risk, education in schools, and voluntary counselling and testing. A recent review showed that many trials of such interventions in communities in developing countries were successful in reducing HIV incidence in the communities where the interventions occurred. ${ }^{8}$ For these strategies to reduce national rates of HIV, however, the combined efforts of the Government and non-Governmental groups are needed, including religious leaders and community development organizations working together to inform and educate the population. There are still very few examples of this integrated approach. One country which has successfully reduced the number of new infections is Uganda, where prevalence has dropped from $14 \%$ in the early 1990 s to around $8 \%$, consistent with reports of delayed onset of sexual activity and marriage, and increased condom use. ${ }^{9}$ Recent data show that HIV rates may also now be falling in Zambia, one of the worst affected countries, where again there is an integrated approach. HIV rates among pregnant girls aged 15-19 in the capital, Lusaka, have halved from around $25 \%$ to $12 \%$ in the last 6 years. $^{2}$

\section{Epidemiology of HIV in India, south and south-east Asia}

No other continent has experienced the extensive spread of HIV that sub-Saharan Africa is suffering from. In part, this may be a result of the age of the epidemic, a factor known to account for some of the recorded differences in prevalence worldwide. ${ }^{10}$ Other areas of the world, however, are now reporting an increasing incidence of HIV. For example, India is currently estimated to have 3.7 million HIV positive persons - up from an estimated 2.7 million in 1998. ${ }^{11}$ The first HIV-positive person was identified in India in 1986, and there has since been a rapid spread of the epidemic in several parts of the country. It is estimated that most of these infections have been acquired through sexual transmission (80\%), with smaller numbers from injecting drugs $(5 \%)$ and from infected blood transfusions $(5 \%)$, and a few through mother to child transmission $(<1 \%) .{ }^{11}$

India, like many other countries, does not have a single HIV epidemic, but has multiple epidemics in different geographical settings and among people with different types of risk. Initial cases were reported among female sex workers in the cities of Mumbai and Chennai, and among injecting drug users in the north-east of the country, especially in the state of Manipur. ${ }^{12}$ Since then, however, there has been a diffusion of the epidemic away from recognized 'high risk groups' and into the so-called 'general population'. The seropositivity rate among pregnant women (taken as representative of the sexually active 'general population' of women of reproductive age) in selected sentinel sites ranges between zero and over 2\% (in the States of Maharashtra and Karnataka), and is as high as $6 \%$ in some areas of slums of the city of Mumbai. ${ }^{13}$ Studies which have examined the prevalence of HIV infection in married women have found that husbands' reported behaviour was often the major risk factor. ${ }^{14-16}$

Most other countries in south Asia have lower HIV prevalence rates than those reported in parts of India. However, the region exhibits high levels of risk in most of the factors which are known to increase population vulnerability: gender inequality, poverty and disparities in income distribution, low levels of formal education and literacy, rural-urban divides which 
lead to high levels of population movement and high levels of inter-country migration - for example, it estimated that 165,000 men leave Bangladesh each year to work abroad. ${ }^{17}$ Given the already high burden of disease, economic poverty and generally poor ranking in tables of global development, the 1.2 billion people who live in the countries of south Asia are at risk of an extended HIV epidemic. The ability of south Asia to prevent such an epidemic will rely upon an openness in recognizing the problem and its challenge, and a concerted multisectoral approach to reduction of individual risk and societal vulnerability.

The south-east Asian epidemic has been well documented in Thailand, where HIV initially spread rapidly in the late 1980s among injecting drug users and between sex workers and their clients. The government acted quickly to set up a comprehensive prevention campaign including enforced condom use in establishments used by sex workers and a mass advertising campaign. ${ }^{18}$ HIV rates have now stabilized and the prevalence in the general population is around 2\%. Meanwhile, neighbouring Cambodia has suffered one of the highest recorded HIV rates in south-east Asia: in 1998, 3.6\% of adults aged 18-45 years were estimated to be HIV positive, including $2.6 \%$ of women of childbearing age. ${ }^{19}$ The country has one of the highest rankings on the Human Poverty Index in Asia, ${ }^{20}$ and a limited inf rastructure with which to cope with the impact of HIV disease.

\section{HIV epidemiology in other regions}

In Europe and the United States of America, the dynamics of the epidemic have been very different, a reflection, perhaps, of these societies' different risks and vulnerabilities (see Table 1 for examples of variables which will differ in prevalence between regions). Mortality due to HIV/AIDS has decreased sharply since the mid-1990s due the availability of antiretroviral drugs The number of new infections, however, is not decreasing, highlighting the need to maintain effective strategies for prevention. For much of the past 2 decades, the risk of acquiring infection has remained highest among men who had sex with men, and injecting drug users. Now the pattern is changing, with heterosexual intercourse the main mode of transmission in the $\mathrm{UK}^{21}$ and other countries in northern Europe. A similar trend is seen in the United States (Figure 2).

In the Caribbean too, heterosexual transmission is the cause of most HIV infections, leading to rates in the general population of around 3-5\% in several countries in the region, including Haiti, the Bahamas and the Dominican Republic. Up to $10 \%$ of pregnant women are estimated to be HIV positive in some urban centres in Haiti. Heterosexual transmission is increasing in Latin America also, where the epidemic was initially concentrated among homosexual men and injecting drug users.

In the year 2000, HIV epidemics have exploded in many countries of Eastern Europe and Central Asia, and the number of infected adults and children has almost doubled to 700,000. The main mode of transmission in this region is injecting drugs. Social and structural factors outlined in Table 1 will shape the epidemic in this region, where socioeconomic instability is already causing an increase in drug use and commercial sex. However, some encouraging strategies for prevention have been put in place. ${ }^{1}$

\section{Conclusions}

Thousands of people continue to be newly infected with HIV every day, contributing to the many HIV epidemics in different regions of the world. The diversity of the epidemics results 


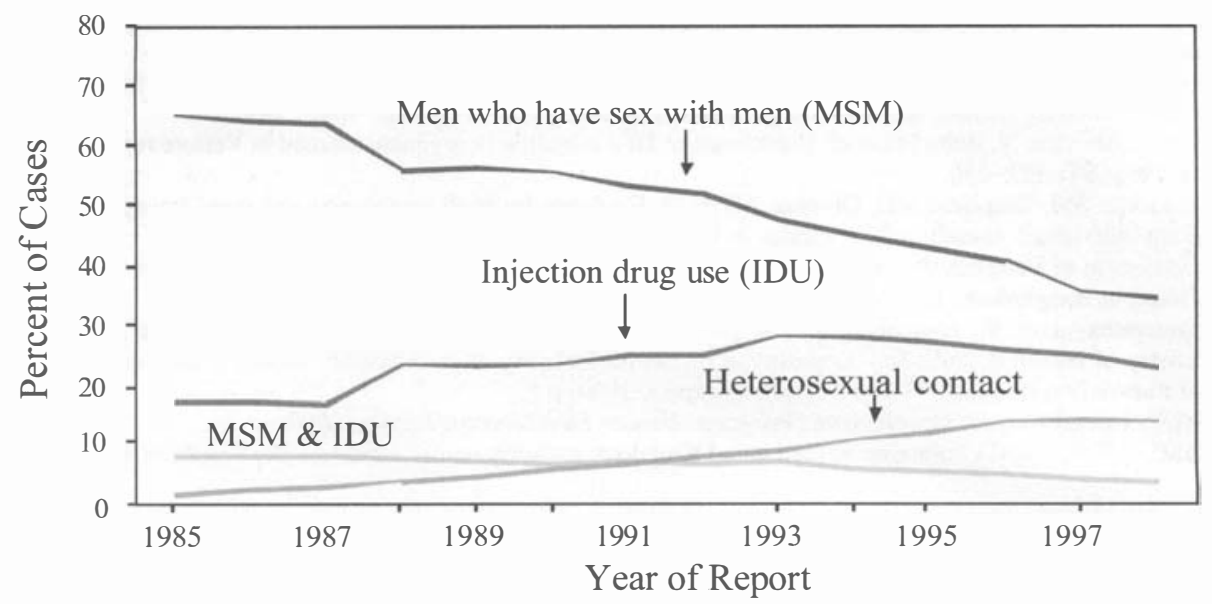

Excludes cases with other or unreported risk pending medical record review and reclassification.

Figure 2. AIDS cases by exposure category and year of report, 1985-1998, United States (source: Centers for Disease Control \& Prevention, National Center for HIV, STD and TB Prevention, Atlanta, Georgia, USA).

from a complex interaction of behavioural, social and biological factors. Sub-Saharan Africa has suffered most, with devastating social and economic consequences. Many of the factors that fuelled the epidemics in Africa are present in other developing countries around the world, and pose a formidable public health challenge. The response to this challenge must be based on the recognition of the diverse risks and vulnerabilities in each population, and must integrate the attitudes and efforts of different sectors of society and the public health authorities.

\section{References}

1 UNAIDS/WHO. AIDS epidemic update. UNAIDS, Geneva, December 2000.

2 UNAIDS/WHO. Report on the global HIV/AIDS epidemic. Geneva: UNAIDS, Geneva, June 2000.

3 Buve. A. for the Study Group on Heterogeneity of HIV Epidemics in African Cities. HIV/AIDS in Africa: Why So Severe, Why So Heterogeneous? 7th Conference on Retroviruses and Opportunistic Infections, San Francisco, CA, USA, February, February 2000 [Abstract S28].

${ }^{4}$ Fleming S, Wasserheit J. From epidemiological synergy to public health policy and practice: the contribution of other sexually transmitted diseases to sexual transmission of HIV infection. Sex Trans Inf, 1999; 75: 13-17.

5 Fink A. Circumcision and heterosexual transmission of HIV infection to men. $N$ Engl J Med, 1987; 316: 1546-1547.

6 Weiss HA, Quigley MA, Hayes RJ. Male circumcision and risk of HIV infection in sub-Saharan Africa: a systematic review and meta-analysis. AIDS, 2000; 14: 2361-2370.

7 Szabo R, Short RV. How does male circumcision protect against HIV infection? BMJ, 2000; 320: $1592-1594$.

${ }^{8}$ Merson MH, Dayton JM, O'Reilly K. Effectiveness of HIV prevention interventions in developing countries. AIDS, 2000; 14: S68-84.

9 Asiimwe-Okiror, G G, Opio A, Musinguzi J et al. Change in sexual behaviour and decline in HIV infection among young pregnant women in urban Uganda. AIDS, 1997; 11: 1757-1763.

10 Over M. The effects of societal variables on urban rates of HIV Infection in developing countries: an exploratory analysis. In: Ainsworth M, Fransen L, Over M (eds) Confronting AIDS: evidence from the developing world. European Commission and the World Bank, 1998.

11 National AIDS Control Organisation. http://www.naco.nic.in/vsnaco/indianscene/update.htm (07/09/00).

12 Pal SC, Sarkar S, Naik TN et al. Explosive epidemic of HIV infection in north-eastern states of India, Manipur and Nagaland. Indian Council for Medical Research. CARC Calling, 1990; 3: 2-6 
13 National AIDS Control Organization. Country Scenario 1997-98. Government of India, Ministry of Health and Family Welfare, New Delhi, 1998.

14 Jacob M, John TJ, George S et al. Increasing prevalence of human immunodeficiency virus infection among patients attending a clinic for sexually transmitted diseases. Ind J Med Res, 1995; 101: 6-9.

15 John TJ, Bhushan N, Babu PG et al. Prevalence of HIV infection in pregnant women in Vellore region. Ind J Med Res, 1993; 97: 227-230.

16 Mehendale SM, Shepherd ME, Divekar AD et al. Evidence for high prevalence and rapid transmission of HIV among individuals attending STD clinics in Pune, India. Ind J Med Res, 1996; 104: 327-335.

17 Government of Bangladesh and UNICEF. Master plan of operations for a programme of services for women and children in Bangladesh, 1993-1995. GOB/UNICEF, Dhaka, 1993.

18 Rojanapithayakorn W, Hanenberg R. The $100 \%$ condom program in Thailand. AIDS, 1996; 10: 1-7.

${ }^{19}$ Ministry of Health (Cambodia). Department of Health Planning \& Information, Health Situation Analysis 1998 and Future Directions 1999-2003 (briefing paper), 1999, p 6.

${ }^{20}$ UNDP. United Nations Development Program, Human Development Report, 2000.

${ }^{21}$ CDSC. AIDS and HIV infection in the United Kingdom: monthly report. Commun Dis Rep CDR Wkly, 2000; 10: $157-160$. 